International Journal of Automotive and Mechanical Engineering

ISSN: 2229-8649 (Print); ISSN: 2180-1606 (Online)

Volume 16, Issue 3 pp. 7144-7154 Sept 2019

(C) Universiti Malaysia Pahang, Malaysia

\title{
Nitinol Reinforced Epoxy Smart Composites with Enhanced Stiffness and Damping
}

\author{
H. R. Shankar ${ }^{1}$ and B. K Goriparthi ${ }^{2 *}$ \\ ${ }^{1}$ Faculty of Mechanical Engineering, GITAM University, \\ Visakhapatnam, India \\ ${ }^{2}$ Faculty of Mechanical Engineering, IIIT Srikakulam, RGUKT-AP, India \\ *Email: bk1381@yahoo.co.in
}

\begin{abstract}
Control of resonant vibrations is an important consideration in designing the composite structures. The mere presence of damping can bring back the resonant amplitudes from infinite to finite. Therefore, the damping parameter is an important parameter to be considered while designing the structures. But damping and stiffness are the two important opposing performance characteristics of the structures. Hence the development of high damping materials without affecting the stiffness is the focus of several researchers. Recently, smart materials are being introduced in polymer composites for better dynamic characteristics which enhance both stiffness and damping whenever required. In the present study, smart epoxy composites with the inclusions of austenitic phase nitinol (smart material) particle are developed and tested for mechanical and structural vibrational characteristics. Results revealed that at a weight fraction of $4 \%$ nitinol inclusion, stiffness, strength, and damping have simultaneously increased.
\end{abstract}

Keywords: Smart composite; shape memory alloy; structural damping

\section{INTRODUCTION}

Structures prone to vibrations need to be designed with materials having high damping capacity and stiffness. Damping capacity and stiffness are the two important opposing performing characteristics of the materials used in structures. Recently polymer composites are replacing conventional metals especially in structures like automobile bodies, body bumpers, due to their high specific properties and the ability to tailor the properties as per the design needs [1]. Despite having better damping properties, polymer composites possess poor mechanical properties compared to metals. This restricts their usage in structures subjected to dynamic loads. Hence there is a demand to develop materials with high damping capacity and stiffness. Recently, shape memory alloys (SMA) popularly known as "smart materials" are included in composites for better mechanical and dynamic characteristics. The two important properties of the SMA that make the material smart are shape memory effect (SME) and superelasticity. SME refers to the phenomenon by which material returns to their predetermined shape upon heating. Super elasticity refers to the material that undergoes a large amount of inelastic strain and recovers their shape after unloading. These two distinct properties for SMA are due to phase transformation from austenite to martensite upon cooling (known as temperature-induced martensite)/ mechanical loading at a critical stress (known as stress-induced martensite) and vice versa upon heating/unloading. 
During phase transformations, SMA absorbs/dissipates energy and tunes its mechanical properties. These unique properties prompted the researchers to use them as reinforcements in composite materials. The stress or temperature where the transformation of phase starts and completes in SMA materials is known as critical stresses and critical temperatures. These critical parameters are important for designing material that suits a specific application. These values can be altered by selecting suitable heat treatment temperature and time [2]. The transformation stresses of the nitinol wires depend on heat treatment cycles. Mechanical properties of composites strongly depend on the bonding of its constituents with the matrix. The rate of reorientation of stress-induced martensite reduces the interfacial debonding [3]. Further, the size of the smart reinforcements also influences the interfacial bonding which in turns affect the mechanical properties. Chaudhury et al. [4] observed the influence of the size of the NiTi fibres in debonding of fibres in nitinol included $\mathrm{Al}$ - matrix SiC composites. However, debonding phenomenon occurs significantly at higher sizes of nitinol particles and no evidence is reported at lower sizes.

Superelastic SMA wires are embedded in resins and fibre-reinforced composites to make them smart. Superelastic SMA wires suppress the propagation of the damage in the composite and increase impact resistance [5]. The stress temperature behaviour of SMA composites is similar to that of SMA wires [6]. This interestingly extended the scope to develop smart composite materials. The stiffness of SMA-composites changes very little with varying prestrain. SMA-composites have an ability to generate high recovery stresses of up to $115 \mathrm{MPa}$ which makes it suitable to use as damping material [7]. Natural frequencies of SMA fibre reinforced composite beams can be controlled effectively if the temperature maintained is above the austenite finish temperatures as compared to martensite finish temperatures of SMA due to a significant increase in density than stiffness [8]. Mechanical properties of composites filled with micro SMA particles and SMA short fibres in epoxy resin were investigated by Run Xin et al [9]. The storage modulus, flexural modulus and loss factor increase with filler content. It was reported the addition of SMA particles presented promising results compared to SMA short fibres. John and Hariri [10] studied the effect of SMA actuation on the dynamic responses of the polymeric composite plates. The alteration of the natural frequencies using SMA to avoid catastrophic failures at resonance was presented and concluded that the alteration of structural properties is possible.

Nitinol included Mg metal matrix composites exhibits better specific damping capacity and specific fracture strength and good mechanical properties [11]. Vibrational damping, tensile and impact properties of the composite were enhanced with the inclusions of pre-strained superelastic SMA fibres in thermoset matrix [12]. Enhancement of fatigue life of glass-fibrereinforced epoxy composites with embedded shape memory alloy wires was reported by Zhenqing Wang et al [13]. Works reported on the usage of SMA are mostly dealt with the enhancement of mechanical properties or controlling vibrations. Most of the works reported are confined to SMA wires. The usage of micro-sized SMA particles in a polymer matrix is very limited and restricted to material characterisation. Evaluation of vibration characteristics of smart composite structures with particle inclusions is seldom found. The present paper is aimed to develop nitinol particle included epoxy smart composite for enhanced mechanical and structural dynamic properties. Smart composite with varying weight fractions of micro-sized SMA particles (of austenite phase) in the epoxy resin are developed. Tensile and flexural properties of the composite were evaluated. For studying the structural dynamic properties, 
vibration tests were conducted on clamped cantilever composite beams and damping ratios were obtained at first two modes.

\section{MATERIALS AND EXPERIMENTAL WORK}

\section{Materials}

$\mathrm{Ni}-\mathrm{Ti}$ shape memory alloy $(\mathrm{Ni}: \mathrm{Ti}=50: 50)$ produced by $\mathrm{M} / \mathrm{s}$ Nanoshell was used in the present study. The average size of SMA particles varies from 1 to 10 micron. The phase transformation temperature for austenite of the Ti-Ni alloy is about $500{ }^{\circ} \mathrm{C}$. ER3 epoxy resin supplied by M/S Allied agencies, India was used as a matrix.

\section{Sample Fabrication}

In order to disperse austenitic phase SMA inclusions at room temperature in epoxy resin, Nitinol particles were annealed at $550^{\circ} \mathrm{C}$. The Nitinol particles were heated to $550^{\circ} \mathrm{C}$ and held for 30 min at the temperature and subsequently cooled to room temperature in air. Differential Scanning Calorimetry (DSC) results conformed austenite phase of the inclusions. Nitinol particles in the austenite phase, with different weight fractions i.e. $2 \%, 4 \%, 8 \%$ and $16 \%$ were mechanically mixed in epoxy resin using a stirrer. After thorough mixing, the mixture was kept in a vacuum oven for removal of air bubbles for an hour. A premeasured quantity of hardener was added to the nitinol particle included resin before it is poured into the mould. PVA (Poly Vinyl Alcohol) was sprayed on the mould for easy removal of the specimens. The moulded samples were cured in the die, at room temperature for 24 hours. After removal of the samples from the mould, specimens were cut as per the requirement for various tests as shown in Figure 1(a) and 1(b).

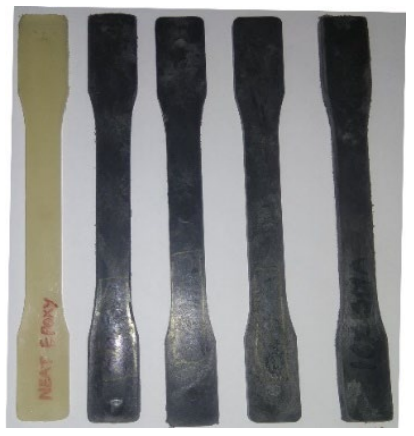

(a)

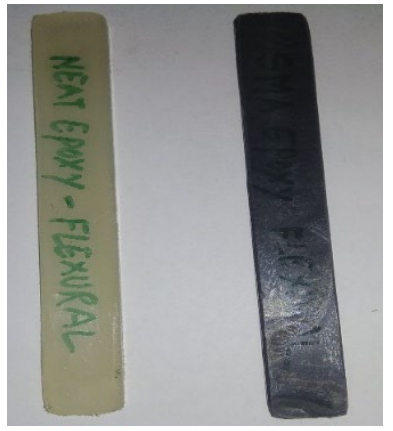

(b)

Figure 1. (a) Tensile and; (b) flexural specimens.

\section{Differential Scanning Calorimetry}

The phase transformation temperatures of nitinol particles were measured using a Differential Scanning Calorimetry (DSC) at temperatures in the range of $140^{\circ} \mathrm{C}$ to $120^{\circ} \mathrm{C}$ under a controlled cooling/heating rate of $10^{\circ} \mathrm{C} / \mathrm{min}$. Both heat-treated and untreated nitinol were tested in DSC to ensure the austenitic phase of the inclusions. 


\section{Tensile and Flexural Test}

In order to characterise the effect of pseudoelasticity, nitinol wire $0.5 \mathrm{~mm}$ diameter of the same grade as that of particles was tested using UTM (make Instron) before and after heat treatment. An extensometer was attached to measure the strain. For the tensile test on wires and composite specimens, the crosshead speed was set at $1 \mathrm{~mm} / \mathrm{sec}$. Both tensile and flexural tests were carried at room temperature as per ASTM standards (ASTM D3039 and ASTM D790 respectively). The standard rectangular specimens with dog bone shape were used for tensile tests and flat test specimens of the size of $125 \mathrm{~mm} \times 10 \mathrm{~mm} \times 4 \mathrm{~mm}$ were used for flexural tests. To avoid the failure in grips during tensile tests, end tabs made of the same material were attached to the samples. During flexural tests, the cross speed was set at $2 \mathrm{~mm} / \mathrm{min}$.

\section{Morphology Study}

The morphology of tensile fractured surfaces was investigated using ZEISS EVO® MA15 scanning electron microscope (SEM). The SEM specimens of very thin sections of area $1 \mathrm{x} 1$ $\mathrm{mm}^{2}$ were cut from tensile fractured composite samples using a diamond knife. Prior to SEM observations, the specimens were coated with gold using the plasma sputter apparatus to make them conductive.

\section{Vibration Test}

Vibrations tests were carried out on the composite beam specimens of size $250 \times 25 \times 4 \mathrm{~mm}$. Structural damping ratios were evaluated for a fixed-free cantilever beam. The specimen was forced to vibrate using an impact hammer (Bruel and Kajer) and responses were captured at the free end using an accelerometer. The damping ratios were evaluated from the frequency response function graphs (FRFs) using half-power points. The schematic diagram of the experimental setup is shown in Figure 2(a). The peaks in the frequency response spectrum are the locations of natural frequencies (Figure 7). Using simple beam bending equation, impact force was chosen for all the cases in such a way that the stress in the nitinol is reached to its critical stress in order to make use of pseudoelasticity property of the nitinol. The system generated impact force versus time diagram during experimentation for the pure epoxy beam is represented in Figure 2(b).

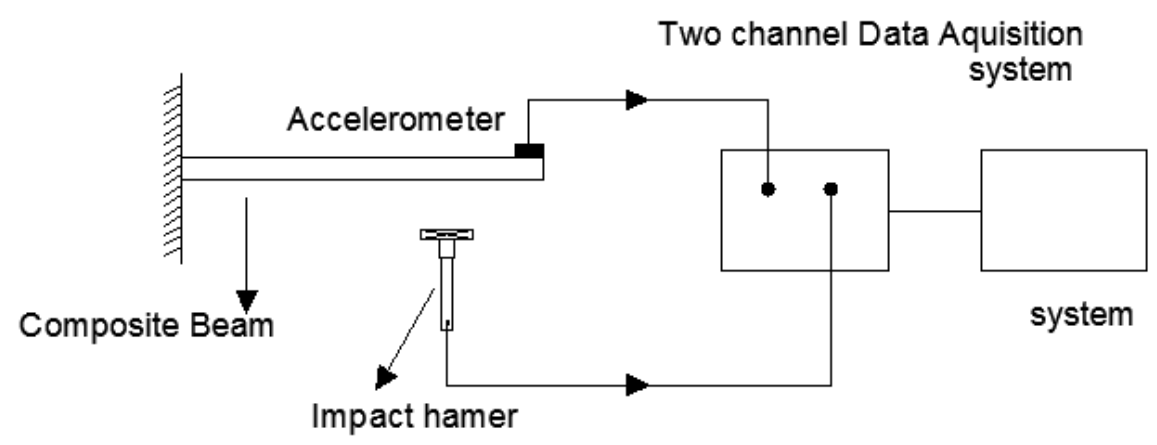

(a) 
$[\mathrm{N}]$

Time(FORCE)

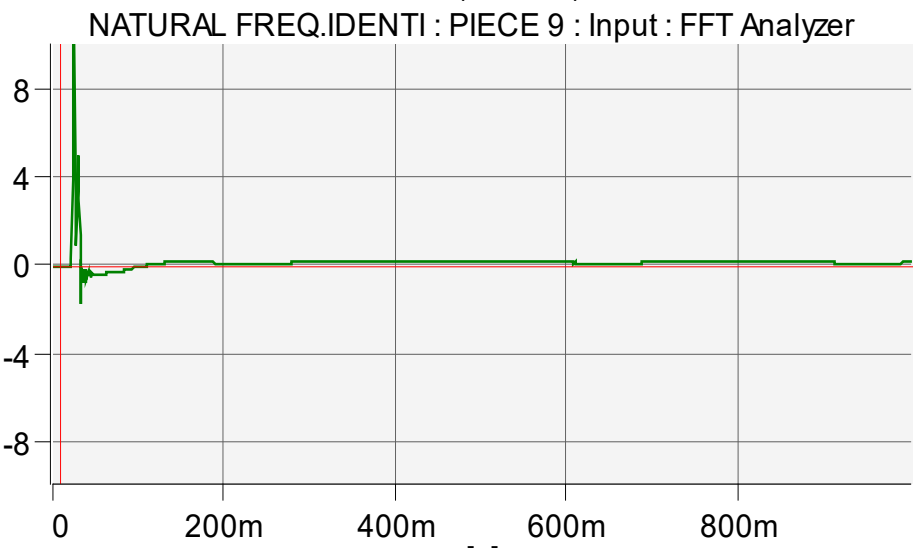

(b)

Figure 2. (a) Experimental set-up for vibration and; (b) impact force vs time on composite beam specimen.

\section{RESULTS AND DISCUSSION}

\section{Differential Scanning Calorimetry (DSC)}

Results obtained from DSC for nitinol (both treated and untreated) are presented in Figure 3. Results reveal that heat treatment of nitinol shifts the phase transformation temperature towards lower side and confirm the austenitic phase at room temperature. During heating for heat-treated nitinol austenitic phase starts at $\left(\mathrm{A}_{\mathrm{s}}\right) 0^{\circ} \mathrm{C}$ and completes at $\left(\mathrm{A}_{\mathrm{f}}\right) 24.5^{\circ} \mathrm{C}$ and for untreated nitinol $\mathrm{A}_{\mathrm{s}}$ and $\mathrm{A}_{\mathrm{f}}$ are $50^{\circ} \mathrm{C}$ and $70^{\circ} \mathrm{C}$ respectively. Similarly during cooling martensite start $\left(\mathrm{M}_{\mathrm{s}}\right)$ and martensite finish temperature $\left(\mathrm{M}_{\mathrm{f}}\right)$ for treated nitinol are $-2^{\circ} \mathrm{C}$ and $-36^{\circ} \mathrm{C}$ and that of untreated nitinol $\mathrm{M}_{\mathrm{s}}$ and $\mathrm{M}_{\mathrm{f}}$ are $36^{\circ} \mathrm{C}$ and $21^{\circ} \mathrm{C}$ respectively.

From the cooling curve of untreated nitinol, it can be inferred that phase transformation takes place from austenite to $\mathrm{R}$ phase (Twinned martensite phase) and then to the martensite phase. It is observed that R-phase starts $(\mathrm{Rs})$ at $76^{\circ} \mathrm{C}$ and finishes $\left(\mathrm{R}_{\mathrm{f}}\right)$ at $51^{0} \mathrm{C}$. It is evident that both phases of martensite and R-Phases co-exist in untreated nitinol at room temperature. The continuous change of heat flow in DSC graphs of untreated nitinol may be due to the recovery of residual stress during the reduction of nitinol into particles.

\section{Tensile and Flexural Properties}

Tensile stress-strain curves of untreated and annealed nitinol wires are presented in Figure 4. It can be observed that critical stress $\sigma_{\mathrm{cr}}$ is around $335 \mathrm{MPa}$ for untreated nitinol wire at which Rphase transforms into a stress-induced martensite. Annealed austenitic nitinol transforms into a stress-induced martensite at $\sigma_{\mathrm{cr}}$ at around $160 \mathrm{MPa}$. During this transformation, significant dissipation of energy takes place due to relative motion between the planes of martensite variants. Below theoretical stress, the material is austenitic and elastic. Similarly, above $\sigma_{\mathrm{cr},}$ the material is observed to be fully martensitic and elastic. The slopes of both the curves reveal that elastic modulus of annealed nitinol is higher than that of untreated nitinol. Tensile modulus for 
untreated nitinol and heat-treated nitinol is $16.67 \mathrm{GPa}$ and $32.25 \mathrm{GPa}$ respectively. Tensile and flexural properties of the pure epoxy specimen and austenitic nitinol particle included epoxy composite specimens at different weight fractions of nitinol are presented in Figure 5(a) and 5(b). It can be observed that tensile modulus, flexural modulus, tensile strength, and flexural strength increase with inclusions of nitinol particles up to $4 \%$ weight fraction and decreased at further higher weight fractions. This may be attributed due to the pseudoelastic property of nitinol particles.

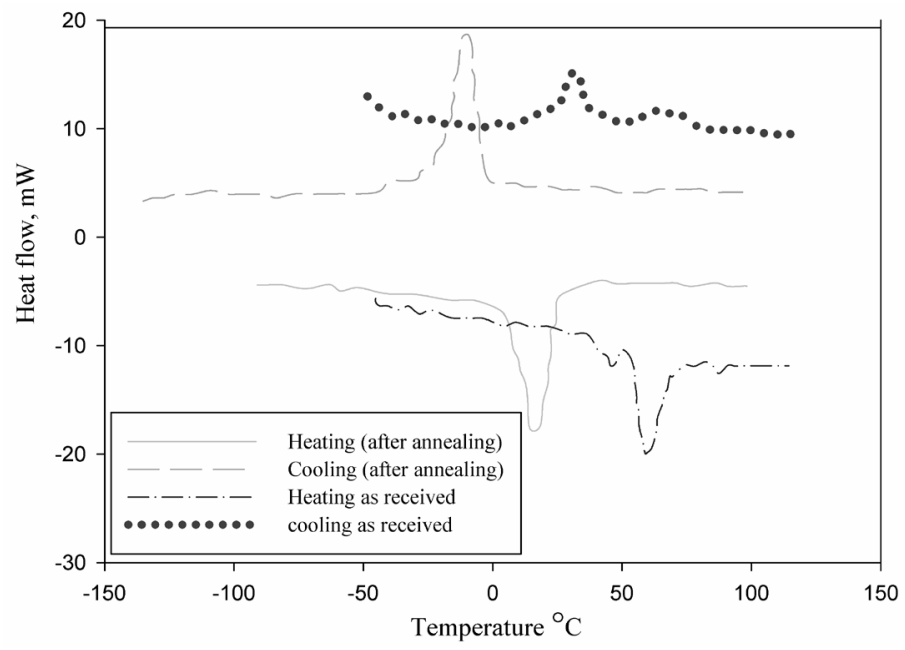

Figure 3. DSC graphs for nitinol particles before and after heat treatment.

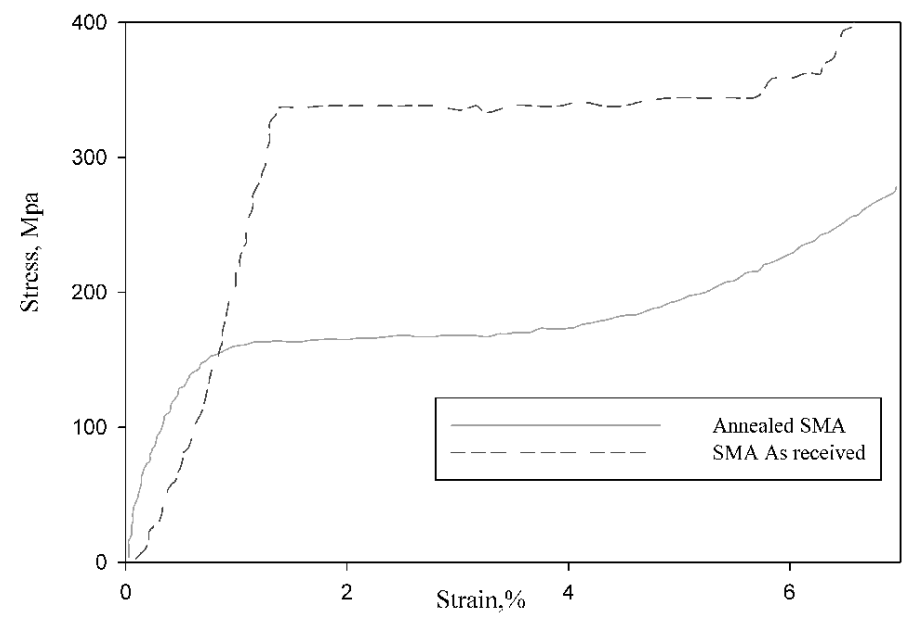

Figure 4. Stress-strain curve for SMA (nitinol) wires. 


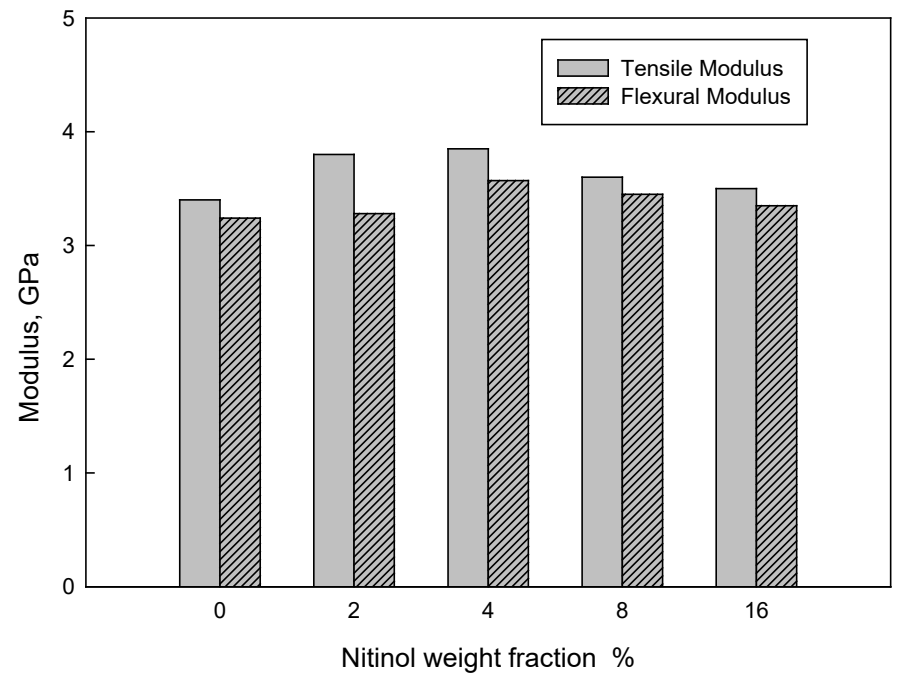

(a)

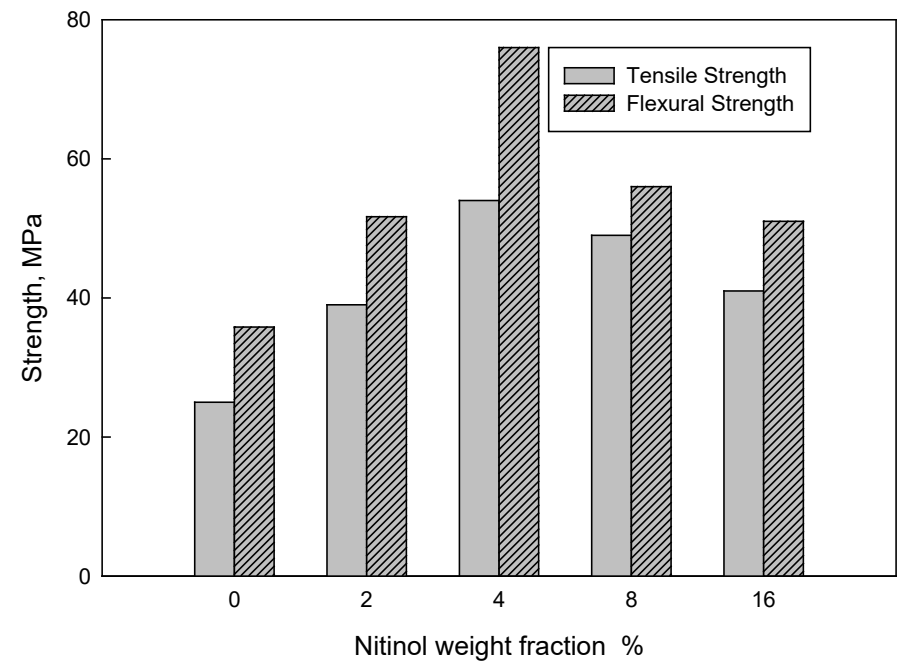

(b)

Figure 5. Variation of (a) moduli and (b) strength with nitinol percentage.

When the stress in epoxy is around $17 \mathrm{MPa}$, the stress in nitinol increases to around 160 $\mathrm{MPa}$ (in order to have strain continuity, nitinol particles act as stress raisers and subjected to high stresses due to stress concentration) and transforms into a stress induced martensite. During the transformation, energy was absorbed, and high composite strength is reported. At higher weight fractions, reduction in both strength and stiffness may be due to poor wetting of the nitinol particles. This leads to de-bonding and poor load transfer between resin and particles. At $4 \%$ weight fraction inclusions, tensile strength and flexural strength increased by 2.16 times and 2.12 times respectively as compared to pure epoxy, whereas a marginal increase in tensile modulus and flexural modulus by 1.2 times and 1.12 times respectively was observed. However tensile and flexural properties increased at all weight fractions of nitinol inclusions as compared to pure epoxy. 


\section{Morphology}

SEM images of tensile fractured surfaces of nitinol included epoxy composite are presented in Figure 6. From the SEM images of composites having higher weight fractions of nitinol, debonding of nitinol particles from epoxy resin and agglomerations are evident. It is observed that debonding tendency increases with weight fraction of inclusions. This debonding could be the reason for lower strength and stiffness at $8 \%$ and $16 \%$ weight fractions as compared to $4 \%$, though it may be higher than pure epoxy.

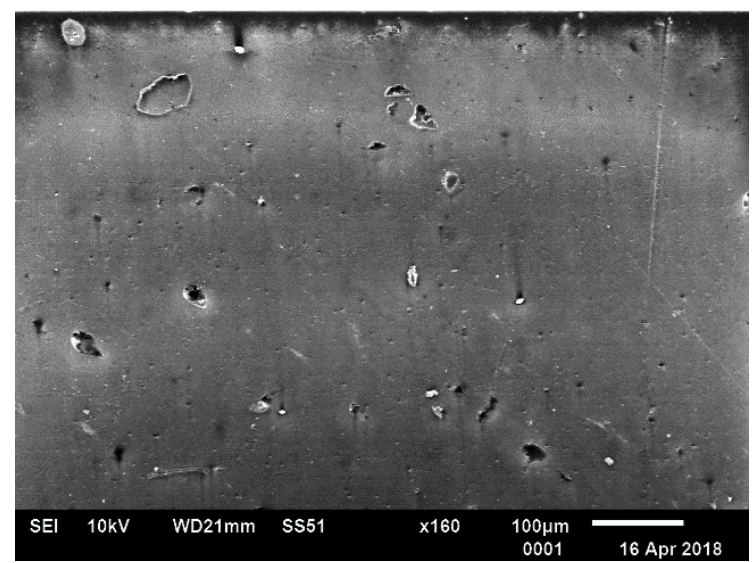

(a)

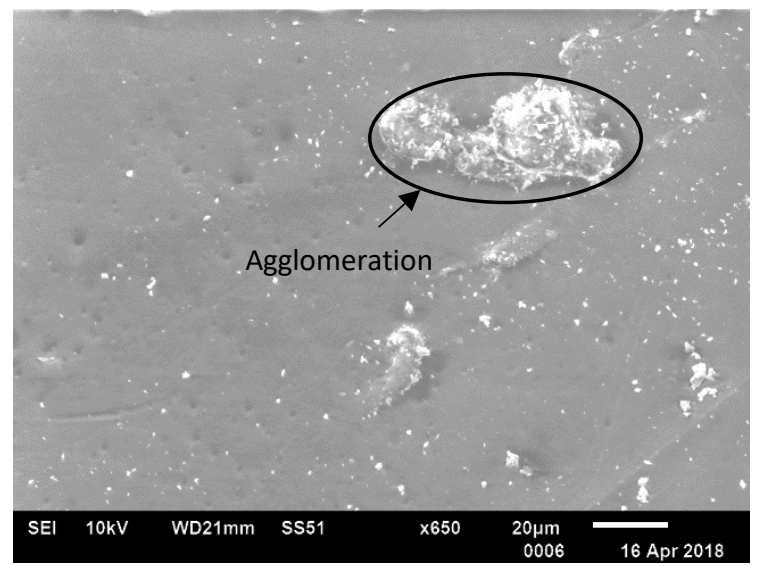

(c)

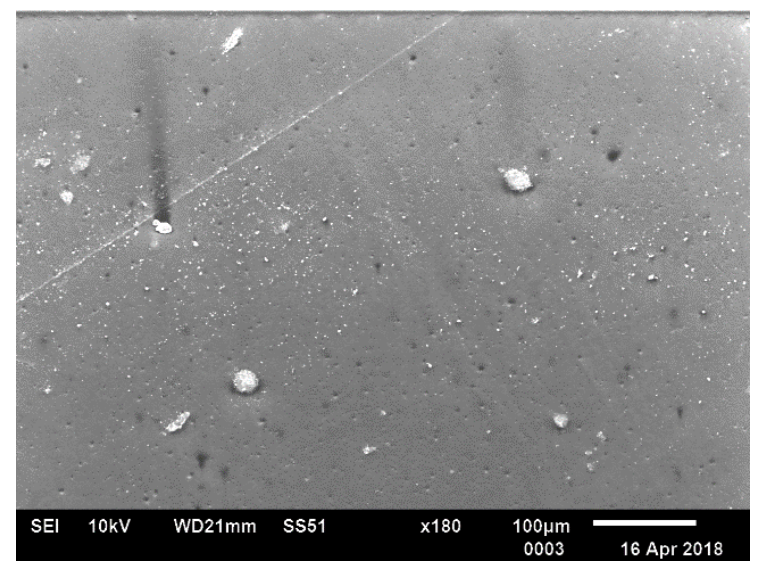

(b)

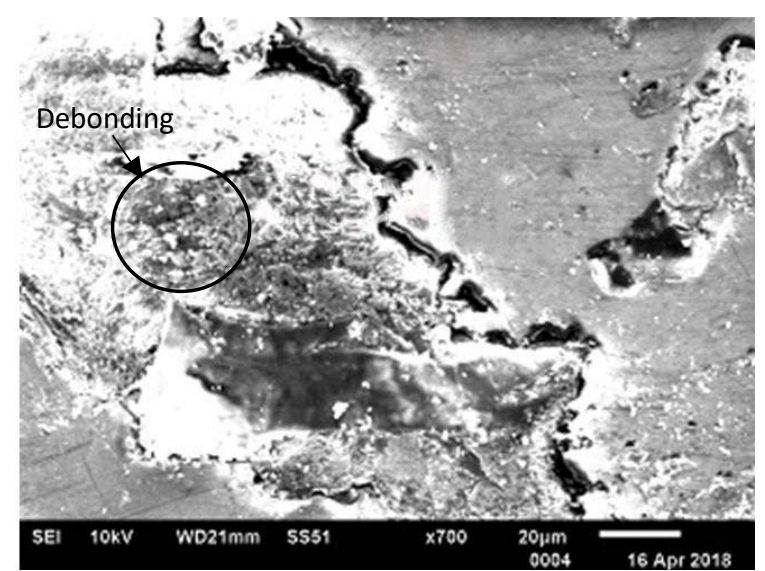

(d)

Figure 6. SEM images of composites with (a) 2 wt.\% (b) 4 wt.\% (c) 8 wt.\% and; (d) 16 wt.\% nitinol.

\section{Vibration Test}

FRFs of smart composite beam specimens obtained during vibrations tests are reported in Figure 7. The first two modal frequencies corresponding to peak amplitudes that exist below $400 \mathrm{~Hz}$ are identified and structural damping ratios at two modes are evaluated using half power points [14]. Modal frequencies and their modal damping ratios are presented in Table 1. It can be seen that modal frequencies shifted towards the higher side with the inclusions of nitinol particles. 
The magnitude of the shift increases with the increasing weight fraction of nitinol inclusions up to $4 \mathrm{wt} . \%$ and thereafter decreased with increase in weight fraction of nitinol. This may be attributed to the increase in stiffness with nitinol inclusions. Similar result i.e. shifting of natural frequencies towards the higher side with the inclusion of SMA wires externally for passive vibration control was observed by Victor Birman [15]. Beyond 4 wt.\%, flexural stiffness of the composite gets decreased and lower natural frequencies were observed at first two modes.

Table 1. Modal frequencies and their modal damping ratios.

\begin{tabular}{lcccc}
\hline \multirow{2}{*}{ Nitinol (wt.\%) } & \multicolumn{2}{c}{ Frequency $(\mathrm{Hz})$} & \multicolumn{2}{c}{ Damping ratio (\%) } \\
& Mode 1 & Mode2 & Mode 1 & Mode2 \\
\hline 0 & 28.75 & 182.5 & 3.21 & 1.55 \\
2 & 33.75 & 212.5 & 3.89 & 1.75 \\
4 & 38.75 & 222 & 4.93 & 1.83 \\
8 & 37.25 & 220.5 & 4.43 & 1.56 \\
16 & 35.25 & 216 & 4.77 & 1.75 \\
\hline
\end{tabular}

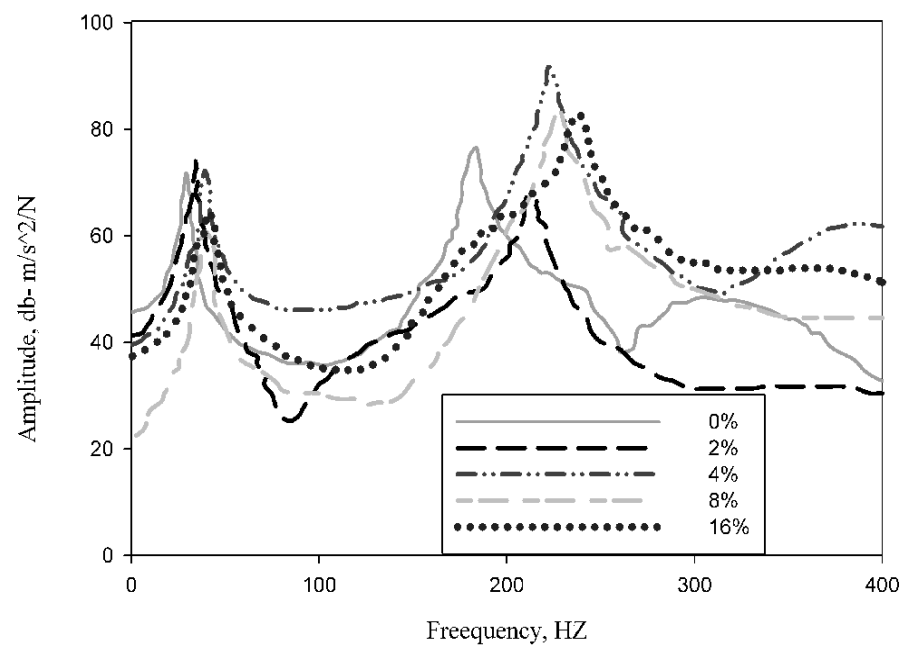

Figure 7. FRFs of composite beam specimens.

Damping ratios at both modes increase with the addition of nitinol particles at all the weight fractions. Enhancement of damping is possible due to superelasticity property of the nitinol inclusions. When the beam vibrates, stresses in beam fluctuate from tensile maximum to zero and then to the compressive maximum. As induced stress in the SMA particles is more than the critical stress, the austenitic phase is transformed into stress-induced martensite and absorbs the energy. This energy is released to surroundings due to reverse transformation during unloading. However, the weight fraction of the inclusions has a significant role in the enhancement of damping of smart composites. Damping increases initially up to $4 \mathrm{wt} . \%$ of inclusions and then decreases at $8 \mathrm{wt} . \%$ and again increases at $16 \mathrm{wt} . \%$. Up to $4 \mathrm{wt} . \%$ inclusions, better load transfer exists between the particles and resin leading to optimum utilization of superelastic property of nitinol. At $8 \mathrm{wt} . \%$, due to poor stress transfer in pursuant to debonding and agglomeration, stress may not rise to critical stress at some of the particles which might 
have led to poor damping. At $16 \mathrm{wt} \%$ of nitinol, due to excessive debonding and agglomerations, the relative motion occurs between particles during vibration which in turn lead to dissipation of energy due to friction between the particles. This coulomb damping due to friction might be the reason for higher damping at $16 \mathrm{wt} . \%$ weight fraction inclusions when compared to that of at $8 \mathrm{wt} . \%$. Thus, it can be concluded that the higher damping at $16 \mathrm{wt} . \%$ inclusions is due to coulomb damping and not because of pseudoelastic property of nitinol particles.

\section{CONCLUSION}

Smart composite samples with addition of austenitic nitinol particles in epoxy resin were fabricated. Mechanical and structural damping properties are evaluated experimentally. Based on the results the following conclusions were drawn.

i. Both tensile and flexural moduli were found to increase with the inclusion of nitinol particles.

ii. Tensile and flexural strengths increase up to 4 wt.\% and then decreases. At 4 wt.\% of nitinol inclusions stiffness, strength, and damping increased simultaneously. At 4 wt.\% of nitinol inclusions, tensile strength, flexural strength, tensile modulus, and flexural modulus increased by $2.16,2.12,1.2$ and 1.12 times respectively as compared to pure epoxy.

iii. Damping ratios increase tremendously at $4 \mathrm{wt} . \%$ of nitinol inclusions at both modes. It is observed that an increase of $53 \%$ at $1^{\text {st }}$ mode and $19 \%$ at $2^{\text {nd }}$ mode.

iv. Further increase in damping at higher weight fractions $(>4 \%)$ is because of coulomb damping due to debonding of nitinol particles and not because of the effect of pseudoelastic property of nitinol.

\section{REFERENCES}

[1] Witik RA, Payet J, Michaud V, Ludwig C, Manson JE. Assessing the life cycle costs and environmental performance of lightweight materials in automobile applications. Composites Part A: Applied Science and Manufacturing 2011; 42:1694-1709

[2] Huang X and Liu Y. Effect of annealing on the transformation behaviour and super elasticity of Niti Shape memory alloy. Scripta Materialia 2001; 45:153-160.

[3] Payandeha Y, Meraghni F, Patoor E, Eberhardt A. Effect of martensitic transformation on the debonding propagation in $\mathrm{Ni}-\mathrm{Ti}$ shape memory wire composite. Materials Science and Engineering A 2009; 518:35-40.

[4] Chaudhury Z, Hailat M, Liu Y, Newaz G. Aluminum-based composites reinforced with SiC particles and NiTi fibres: influence of fibre dimensions and aging time on mechanical properties. Journal of Material Science 2011; 46:1945-1955.

[5] Pappada S, Rametta R, Toia L, Coda A, Fumagalli L, Maffezzoli A. Embedding of superelastic SMA wires into composite structures:evaluation of impact properties. Journal of Materials Engineering and Performance 2009; 18:522-530.

[6] Payandeh Y, Meraghni F, Patoor E, Eberhardt A. Debonding initiation in a NiTi shape memory wire-epoxy matrix composite Influence of martensitic transformation. Materials and Design 2010; 31:1077-1084. 
[7] Kelly AT, Schrooten J, Zheng Y, Stalmans R. Thermomechanical characteristics of shape memory alloy composites Part II, Materials Science and Engineering A 2004; 368:299-310.

[8] Lau K, Zhou L, Tao X. Control of natural frequencies of a clamped-clamped composite beam with embedded shape memory alloy wires. Composite Structures 2002; 58:3947.

[9] Zhang RX, Ni QQ, Natsuli T, Iwamoto M. Mechanical properties of composites filled with SMA particles and short fibres. Composite Structures 2007; 79:90-96.

[10] John S, Hariri M. Effect of SMA actuation on the dynamic response of polymeric composite plates. Composites: Part A 2008; 39:769-776.

[11] Lia DS, Zhanga XP, Xionga ZP, Maib YW. Lightweight NiTi shape memory alloybased composites with high damping capacity and high strength. Journal of Alloys and Compounds 2019; 490: L15-L19.

[12] Raghavan J, Bartkiewicz T, Boyko S, Kupriyanov M, Rajapakse N, Yu B. Damping, tensile, and impact properties of superelastic shape memory alloy (SMA) fibrereinforced polymer composites. Composites: Part B 2010; 41: 214-222.

[13] Wang Z, Xu L, Sun X, Shi M, Liu J. Fatigue behaviour of glass-fibre-reinforced epoxy composites embedded with shape memory alloy wires. Composite Structures 2017; 178:311-319.

[14] Rao SS. Mechanical vibrations, 4th ed. New Delhi:Pearson Education; 2004.

[15] Birman V. Shape memory elastic foundation and supports for passive vibration control of composite plates. Journal of Solids and Structures 2008; 45:320-335. 